\title{
TCOM \\ Witnessing glaciers melt: climate change and transmedia storytelling
}

\section{Anita Lam and Matthew Tegelberg}

Abstract

Keywords

DOI

Introduction
The Extreme Ice Survey (EIS) is an exemplary case for examining how to effectively communicate scientific knowledge about climate change to the general public. Using textual and semiotic analysis, this article analyzes how EIS uses photography to produce demonstrative evidence of glacial retreat which, in turn, anchors a transmedia narrative about climate change. As both scientific and visual evidence, photographs have forensic value because they work within a process and narrative of witnessing. Therefore, we argue that the combination of photographic evidence with transmedia storytelling offers an effective approach for future scientific and environmental communication.

Representations of science and technology; Science communication: theory and models; Visual communication

https://doi.org/10.22323/2.18020205

Submitted: 3rd October 2018

Accepted: 4th February 2019

Published: 4th March 2019

In 2005 and 2006, James Balog embarked on two photographic expeditions for National Geographic to record the rapid recession of the Sólheimajökull Glacier in southern Iceland [Appenzeller, 2007]. What Balog saw on these expeditions was a revelation that would become the source of a continuing obsession. Initially a climate change skeptic, it was seeing and photographing the "dying terminus" of these glaciers that Balog credits with converting him into a believer in climate change. As he explains, "[it] has been a revelation for me, to realize I'm in the midst of monumental geologic change that's going to change the face of the Earth forever, and I've got this tool, this camera, with which to witness the change and to bring the story back" [Ritchin, 2010, p. 82]. Consequently, Balog and his network of scientific collaborators developed a method for speaking on behalf of these disappearing glaciers by establishing the Extreme Ice Survey (EIS) in 2007. Since then, EIS has continuously recorded global glacial recession in several locations with the help of sophisticated camera technology. Using a combination of time-lapse and still photography, Balog and the EIS team have produced a comprehensive body of work that offers compelling visual and scientific evidence of climate change. 
Drawing on past credentials as an internationally renowned nature photographer, James Balog has brought the EIS project, and its time-lapse photography, to the attention of a wide range of different audiences. EIS's images have been featured in widely circulated print magazines, such as National Geographic and Popular Photography, and on the websites of influential legacy and digital news media, such as The New York Times, The Guardian, and Huffington Post. EIS's images have also travelled to museums and galleries around the world as part of exhibitions that aim to educate the public about global warming. In 2012, the critically acclaimed, Emmy-award-winning documentary Chasing Ice was released; the film tells the story of EIS, and its ongoing efforts to deliver evidence of climate change to the public.

Featured in so many different media contexts, each targeting a different segment of the public, the EIS project provides an exemplary case for examining how to effectively communicate scientific knowledge about climate change to the general public. Taking into account the twofold mission of the EIS - that is, to produce a persuasive body of visual evidence to convince the public of climate change, and to bring the story of dying glaciers to the public - this article examines how EIS's photography becomes a form of demonstrative evidence that enables multiple audiences to vicariously bear witness to climate change. The photographic evidence provided by the time-lapse images makes it possible for the public to see glacial retreat with their own eyes. Further, we argue that these photographs underpin a transmedia narrative about climate change. Hence, what differentiates EIS from other approaches to climate change communication is a narrative structure that reaches across a broad range of different media contexts, platforms, and formats.

Communicating climate science to the public: witnessing and transmedia engagements with science
An extensive body of research has been dedicated to examining how climate science is communicated to the public in traditional mass media [e.g. Boykoff and Boykoff, 2004; Painter, 2010], and increasingly on social media platforms like Twitter [e.g. Cody et al., 2015; Williams et al., 2015]. An influential strand within this research has grappled with how to effectively communicate climate science to disinterested audiences, particularly those with limited everyday experience or knowledge of this abstract scientific phenomenon. Seeking to address this question, scholars have analyzed representations of climate change across a range of different media to determine their efficacy in enhancing public understandings of climate science, and in motivating greater public action [Moser, 2009; Moser, 2016]. A growing portion of this literature has concentrated on visual representations of climate change [e.g. Doyle, 2007; Smith and Joffe, 2009; O'Neill and Smith, 2014]. These scholars have found that while spectacular images of climate change, such as eroding shorelines and polar bears, play a powerful symbolic role in media discourses, they tend to distance audiences from the lived experiences and realities of climate change [León and Erviti, 2015].

Others have sought to deepen our understanding of how different audiences respond to and engage with climate change communication [e.g. Nisbet, 2009; Moser and Dilling, 2011; Sakellari, 2015]. Moser and Dilling [2011, p. 162] argue that climate change communicators have made problematic assumptions about audiences that must be overcome to close the gap between science and action, and to cultivate more "effective and meaningful public engagement" with climate science. For example, they problematize communicators that view climate change 
as simply an informational problem that can be resolved by providing the public with more information [Moser and Dilling, 2011, p. 163]. On the contrary, audiences are more inclined to engage with climate narratives when climate framings, messages and messengers are tailored to specific communication channels that appeal to and actively engage particular kinds of audiences [Moser and Dilling, 2011, p. 165-68]. Cinematic representations of climate change, for example, can appeal to wider audiences because motion pictures can expose them "to narrative, emotional climate change storylines, inducing a [...] moral framing of climate change" [Sakellari, 2015, p. 837]. From these insights, we argue that the theoretical concepts of witnessing and transmedia storytelling have the potential to engage audiences in similar kinds of ways, in order to overcome the science-action gap.

When it comes to conceptualizing "witness," Peters [2001] notes that the term "witness" involves all three stages of the transmission model of communication, including the actor who bears witness, the text itself, and the audience that witnesses. Because witnessing itself "presupposes a discrepancy between the ignorance of one person and the knowledge of another" [Peters, 2001, p. 710], it can be tied to the problem of communication in general and the deficit model of science communication in particular. Implicitly identified as a problematic mode of climate change communication by Moser and Dilling [2011], the deficit model is a top-down model of unidirectional information transmission, advocating that scientists communicate their knowledge to an ignorant general public [Bucchi, 2008; Bensaude Vincent, 2014]. Following this model of communication, scientists have constructed themselves as expert witnesses in courtroom trials [e.g., Jasanoff, 1992; Smith and Wynne, 1989], and mobilized the broader concept of human witness, particularly the eyewitness, in the process of fact-making in both science and law [Shapin and Schaffer, 1985]. In our current period of media expansion, however, witnessing has been tied to moral responsibility. According to Ellis [2000, p. 1], witnessing in the age of audiovisual media ensures that "we cannot say we do not know." Thus, to witness an event is to, in some way, be responsible to it. Such moral responsibility requires a greater level of viewer participation and action than was supposed by past practices of passive media consumption.

Notably, this article links the production of direct and vicarious witnesses to a more participatory model of science communication, one that takes cues from what Henry Jenkins [2009a] has called "transmedia storytelling." When media consumers are conceived as witnesses - in this case, of the devastating effects of climate change on glaciers - they do more than passively watch the unfolding of events. Witnessing is an active, participatory experience, particularly in media spectacles of global events [Howie, 2012], and as such, can take on the different levels of interactivity posited by transmedia storytelling. According to Jenkins [2006], transmedia storytelling develops across a number of different media contexts, with the strengths of a particular media form or platform helping to establish new layers of meaning and entry points into an evolving story. While a transmedia story can emerge in a particular medium, its producers rely on other media to expand the scope of the narrative and generate wider appeal for their story. Unlike the deficit model [Trench, 2008], then, transmedia storytelling assumes diverse audiences for science - some more active than others - as well as multiple approaches to communicating with those audiences. While transmedia storytelling methods have been widely adopted in entertainment, advertising and public relations, they have garnered less interest in science and education 
communities [Moloney and Unger, 2014], even though they can potentially allow science communicators to develop more active and participatory forms of engaging with the public. By activating audiences as witnesses to the event of climate change, transmedia storytelling holds the potential to bridge the science-action gap in climate change communication [Moser and Dilling, 2011], precisely because audiences have a stake in the outcome of climate science - namely, a stake in ensuring the planet's well-being. The ensuing analysis provides concrete examples of how transmedia storytelling principles can be mobilized by science communicators to enhance public engagement with climate science.

Method: transmedia storytelling meets science communication
In sum, our research is informed by two main questions: how is the vicarious witnessing of climate change structured and made possible by the EIS project? How can scientific evidence of climate change be translated through photography and transmedia storytelling, in order to more effectively communicate and engage the general public? We address these questions by examining news stories, interviews, public appearances, films, photographs, and publications featuring EIS, all of which have resulted in more than 500 million online impressions [Keppler Speakers, 2018]. Our sample consists of over 200 media texts, including secondary media texts produced about EIS and primary materials developed by EIS communicators. We analyze this sample through close textual and semiotic readings [Barthes, 1972; Bryman, 2004], combining these approaches in order to identify and critically assess the patterns of representation produced by and about EIS. Given this choice of method, we investigate media representations - specifically, in terms of transmedia principles - irrespective of an author's intent or design. In doing so, we acknowledge that semiotic approaches have not only infamously signaled 'the death of the author' [Barthes, 1977], but also assumed that producers' intentions can diverge from the actual ways that representations circulate, and are consumed by audiences. Consequently, it is noteworthy that EIS did not intentionally plan to use transmedia strategies for communicating their findings (email correspondence with EIS communications director, 12 December, 2018), but stories about and by EIS, nonetheless, adhere to particular transmedia storytelling principles, which can account for their effectiveness across the mediascape.

Thus, our subsequent analysis is grounded by the application of five of Henry Jenkins' [2009a; 2009b] seven principles of transmedia storytelling. We have omitted Jenkins' principles of seriality and subjectivity from this analysis, not only because they do not apply to the EIS narrative, but also because they seem less relevant to scientific communication in general. For example, the principle of seriality refers to (primarily fictional) storytelling where characters and plot lines are developed and dispersed across multiple media contexts in sequential narrative installments. The EIS narrative about receding glaciers, by contrast, maintains a consistent storyline and cast of relevant actors, and is not told in an episodic format. Instead, the same story is repeated to different audiences in different media contexts and formats. Similarly, EIS's claim to objectivity runs counter to the principle of subjectivity, which refers to extending the world of the story by exploring different perspectives, such as from secondary characters. EIS's storytelling does not allow for subjective interpretations that might construe glacial retreat as non-scientific, speculative, and unrelated to climate change. Further, the 
inaccessibility of EIS's glacier sites, as we will soon discuss, does not allow for more viewpoints than those presented by EIS's camera system.

Witnessing climate change in action and telling the story of the ice
In our analysis, we consider how the Extreme Ice Survey produces the direct and vicarious witnesses that become central to their transmedia story of melting ice. Foregrounded as the primary nonhuman actor in EIS narratives about climate change, the ice is made to speak for itself through the extraordinary equipment invented by EIS. EIS focuses on the ice because its founder, James Balog, is certain that "the story [of climate change] is in the ice, somehow"; and "[i]f the story the ice is telling could be heard by everyone, there would no longer be any argument about whether or not humans are causing global warming" [Orlowski, 2012]. To visually establish the factual story of climate change, EIS offers ground-level photographs of extreme ice loss, departing from typical scientific visualizations, such as satellite measurements, computer modelling, and statistics. In doing so, its on-the-ground images can elicit not only a visceral response from viewers but also provoke a sense of immediacy [Burkhart et al., 2017]. In the production of these photographs, EIS inadvertently transforms its visual evidence of climate change into a media form that adheres to and modifies the following principles of transmedia storytelling:

\section{Worldbuilding through technological witnesses}

Henry Jenkins [2009b] describes the principle of worldbuilding as a means for consumers to engage more directly with the world(s) represented in the narrative. While Jenkins' examples have predominantly featured fictional worlds from entertainment media, in which fans treat fantastical realms as real spaces that intersect with their own lived realities, it is possible to consider how worldbuilding manifests in the case of EIS's efforts to bring the reality of glacial retreat to the general public. While fictional texts invent and design new worlds, EIS documents and maps the existing glacial world. Because of the remoteness, inaccessibility and extreme cold weather conditions that characterize many of the world's glacier sites, these locations may be considered so far removed from the lived experience of the general public as to be foreign Otherworlds. These are sites that few people will ever see for themselves; they exist in conditions that challenge most technological attempts to visually capture them, even causing numerous malfunctions to EIS's equipment (e.g., timer failures, exploding batteries, injured cameras due to heavy snowfall and pecking birds). EIS's photographs of melting glaciers, then, requires technological innovations to capture what remains for most an unseen world.

Travelling on foot and horseback, by dog sled and ski, and on helicopters and fishing boats to the geographical extremities of the world, the EIS team has set up a network of cameras at 18 different glacier sites. These different locations, including Antarctica, Greenland, Iceland, Alaska, the Nepalese Himalayas, and the Rocky Mountains, were carefully selected by a team of internationally distinguished glaciologists, in order to provide a good representation of regional ice behaviour [Balog, 2009a]. At each of these sites, EIS has deployed between 27 and 48 time-lapse Nikon D-200 cameras. Powered by a custom-made combination of batteries, solar panels and voltage regulators, the camera system is engineered to survive in adverse weather conditions for 2.5 years. Waterproof and dustproof 
Pelican cases, designed to withstand $160 \mathrm{mph}$ winds and temperatures as low as minus 40 degrees Fahrenheit, protect the cameras, which are then mounted on sturdy Bogen tripod heads and secured against the elements with aluminum and steel anchors [Balog, 2009a]. Programmed to automatically take images every half-hour during every hour of daylight, each camera records between 4,000 and 9,000 frames annually, contributing to an archive of images that exceeds one million frames [Open Space Institute, 2018]. Consequently, the scope and scale of the EIS project sets it apart from past scientific-photographic expeditions.

As a project that relies on a permanent network of ground-based, glacier-watching surveillance cameras, EIS has promoted its camera system as one of its major achievements. Strikingly, the time-lapse camera system allows for the inclusion of technological witnesses in the process of visualizing, monitoring, and recording glacial change. While the human members of the EIS team occasionally visit the cameras (e.g., to fix failing equipment and retrieve flash cards), the cameras - affectionately described by Balog [quoted in Orlowski, 2012] as his "little robot friends" — constantly remain on site. They reveal as much as help build a factual world of alarming ice loss in two ways.

First, the time-lapse cameras assemble the visual evidence of glacial retreat on an hourly and daily basis. They have been positioned to observe how "[g]laciers can disappear in hours or days - with not a single human present to witness the change, let alone preserve a memory of what is gone" [American Society of Media Photographers, 2013]. Serving as direct eyewitnesses to the glaciers' disappearance, these self-registering instruments work tirelessly to let nature speak for itself, and faithfully transcribe that which is said. According to Daston and Galison [2007], automatism and photography produce "objective images." Untouched by human hands, the images are not contaminated by human interference, and are not tainted by human subjectivity. Consequently, the photographs automatically produced by Balog's "robot friends" are examples of mechanical objectivity. Because the machines are incapable of speculating or theorizing, they cannot themselves influence what they see and capture. The ever-alert cameras mechanically preserve the world of ice onto the flash card in ways that make it difficult for climate change deniers to claim willful human interference and manipulation during the process of image-making.

Secondly, worldbuilding is made possible not only through the documentary film Chasing Ice, but also by EIS's placemarks within the Google Earth application.

Launched in 2009, the collection of placemarks allows ordinary users to see each of EIS's selected glacier sites (or each of the locations where EIS has set up a permanent camera system), and to monitor glacier melting at those locations from their own homes. While EIS, as producers, are able to share more of what the team has documented and learned through this interactive online media platform, engaged audience members can also participate in the process of storytelling, deepening their emotional connection to and knowledge of the material. Using Google Earth, for example, users can potentially conduct their own visual analysis of glaciers, by comparing EIS's images to other official data sources within the application, such as the glacier database run by the National Snow and Ice Data Center. 
According to Jenkins [2009a], immersion refers to the ability of the consumer to enter into the world of the story. As one of the driving forces behind the creation of cinema and motion pictures in general, immersion stems from a desire to not only "enter a story or travel to a faraway land," but also from a longing "to see the future of landscapes of the past" [Hayao Miyazaki, quoted in Jenkins, 2009a]. It is the latter longing that EIS addresses through its production of time-lapse photographs of extreme ice loss. Remarkably, its time-lapse photography also plays a crucial role in producing vicarious human eyewitnesses of melting glaciers. By the term "vicarious witness," we refer to an indirect experience of witnessing deployed to convince more members of the general public of a scientific fact. Vicarious witnesses expand the number of possible witnesses of a scientific phenomenon beyond a limited number of direct eyewitnesses. It does so by allowing people to witness things that they cannot experience directly. Vicarious witnesses are especially important to the EIS project for two reasons: one, given the publicly inaccessible locations of the glaciers under study, there are few, if any, direct eyewitnesses of glacial change. Two, glacial change, aside from major calving events, is not immediately visible to human perception, even if human eyewitnesses were to be present. Moreover, vicarious witnesses are made possible through immersion in the story of glacial retreat.

Both witnessing and immersion, in this instance, are tied to the act of seeing glacial change. Because this particular sight does not appear naturally, it needs to be made through a process of collating static photographic shots into a motion picture. Specifically, EIS's use of time-lapse photography transforms glacial time into a temporal perspective that makes sense to humans, translating an extremely long-duration timescale into anthropocentric time. As John Urry [2009, p. 182-195] has described, "glacial time," a temporal regime distinct from clock time and instantaneous time, refers to the long temporality of changes in natural environments that can span millennia, and occur at speeds imperceptible to humans. As "nonhuman" time, glacial time must be placed into and experienced at a human timescale if humans are to act on behalf of melting glaciers. The other major achievement of EIS, then, lies in its use of time-lapse photography as a technique for showing and speeding up the movement of vanishing glaciers. Notably, EIS is working within a tradition where time-lapse photography has been envisaged since the beginning as a scientific aid [Parkinson, 1995, p. 7]. Beginning with Wilhelm Pfeffer's 1898 recording of the eleven-day growth of beans, scientists have used time-lapse devices to not only record and chart natural growth movements, but to also make visible what is otherwise invisible to the human senses. While time-lapse imaging has been used to visualize plant growth, and endow such growth with a vivid sense of vitality [Gaycken, 2012], EIS uses the same technique to visualize the death of glaciers, and endow such death with a sense of devastation. By animating the death of melting glaciers through time-lapse photography, EIS makes a case for the ways in which the photographed movement of ice is itself evidence of climate change.

\section{Drillability and spreadability: making the case for climate change}

EIS's time-lapse photography becomes the primary evidentiary text that anchors its over-arching story of climate change. It is touted in James Balog's TED 
talk [2009b] as "time-lapse proof of extreme ice loss," and by various news media outlets as the photographs that may "convince you about climate change" [Harvey, 2017] and "save the planet" [Rothman, 2012]. Not only are these time-lapse images circulated across multiple media platforms as scientific proof, they can also simultaneously invite a particular mode of audience engagement - namely, what Jason Mittell calls "drillability" [Jenkins, 2009a]. Writing about fictional narratives, Mittell [quoted in Jenkins, Ford and Green, 2013, p. 135] describes drillability as an audience member's "vertical descent into a text's complexities," encouraging "forensic fandoms" to flourish as viewers dig deeper for clues to better understand the story and its telling. Although the clarity of EIS's story does not seem conducive to the establishment of fandoms per se, or at least not in the same way as fictional media franchises with more open-ended narrative structures, drillability is an interesting principle to think through in this case study, precisely because it is a forensic metaphor of audience engagement that aligns with EIS's goal.

EIS's mission is to make a case for climate change. However, the idea of "making a case" is premised on a legal analogy: in Balog's conceptualization, the time-lapse images are "almost like forensic evidence" that EIS is "bringing [...] back to the jury of the public" [Moutinho, 2017] for review. Because EIS's time-lapse images are addressed to the court of public opinion, it is important to consider how these images appeal to the public as a form of demonstrative evidence. Demonstrative evidence allows for properly verified photographic evidence to speak for itself, serving in court as a "silent witness" [Golan, 2004]. Prior to more contemporary understandings of photographs as a form of demonstrative evidence, courts in the US relied on the doctrine of illustrative evidence. When photographs are treated as illustrative evidence, they must be accompanied by a human eyewitness who can testify under oath to the accuracy of the visual image. While the notion of illustrative evidence was a judicial attempt to wrangle and mitigate the persuasive impact of machine-made testimonies in the $19^{\text {th }}$ century, it has since been eclipsed by demonstrative evidence as a recognizable alternative for deploying visual evidence in court [Mnookin, 1998], and to the general public. Tied to the widespread belief in photographic truth - that is, the idea that the photograph is a more authoritative and privileged kind of evidence than other visual representations because of its ability to transcribe nature directly - demonstrative evidence, by the early $20^{\text {th }}$ century, came to refer to evidence that expressed itself directly to the senses [Mnookin, 1998]. Because of its sensory appeal, it could provide a compelling form of proof in and of itself. Hence, photographic evidence no longer needed to be "coupled with human agency [in order] to express what it contained" [Golan, 2004, p. 209].

Turning to EIS's time-lapse images, we note that they have been circulated as a form of demonstrative evidence. In touring exhibitions, these images travel without accompaniment by human EIS representatives. Standing in as a "mute witness" of changing ice forms, these photographs allow human viewers to vicariously witness how climate change is impacting glaciers. By appealing to the viewer's senses, the images render knowledge of climate change visible in a compact and persuasive form, because they are produced and consumed as an evidentiary product that conforms to legal and scientific criteria of reliability. When drillability is applied to EIS's photography, audiences serve as both vicarious witnesses and jury members. They judge the claim of climate change by potentially drilling down on further evidentiary clues to its existence and impact. For example, 
on the EIS website a whole range of educational materials have been developed and hyperlinked in order for audiences to learn more about glaciers themselves.

Beyond drillability, the different ways global audiences can interact with the EIS story align with Jenkins' opposing principle of "spreadability." In transmedia storytelling, spreadability refers to "the capacity of the public to engage actively in the circulation of media content through social networks and in the process expand its economic value and cultural worth" [Jenkins, 2009a]. The multimedia format of EIS photography makes these texts versatile, and thereby well-suited for circulation across many platforms and contexts. Furthermore, the spreadability of these photographs allows for varying modes of audience engagement and interactivity, depending upon the context in which the texts are encountered. This, in turn, affects how audiences engage with EIS, in some instances as individual viewers, and in others as part of a collective viewing experience. This also allows more casual members of the audience to become aware of the science of glacial retreat without the level of commitment that drillability demands. In sum, the EIS story is spreadable because its photographs and videos, particularly in digital form, are portable, shareable, and easy-to-circulate [Jenkins, Ford and Green, 2013].

To visualize the spreadability of EIS's story, Figure 1 maps the various ways in which diverse audiences have been exposed to the EIS project since it was founded in 2007. In addition to over 100 multimedia presentations and more than 500 million online impressions [Keppler Speakers, 2018], Figure 1 quantifies the impressive size of EIS's audience, which includes a total of 107,104 social media followers (as of September 2018) and over 66 million viewers of EIS's offline and online video-related material. The Figure reveals the mix of old and new media forms and platforms that EIS has employed to bring its story of dying glaciers to diverse audiences. Further, its colour scale categorizes the varying degrees of audience participation that have been encouraged by different media forms and settings. The scale runs from cooler to warmer colours, with the former evoking less active forms of witnessing and engagement, and the latter representing more interactive ones. For example, EIS's photographs have been displayed in physical exhibitions at art galleries, airports, and climate summits. They appear in audiovisual media (coded in green in Figure 1) and print publications (coded in blue). Interestingly, these photographs are also featured in interactive displays (coded as orange), such as the current "Extreme Ice" exhibition at Chicago's Museum of Science and Industry. The museum display encourages museum-goers to actively engage with the exhibit beyond that of listeners, viewers, and readers, by scrutinizing the artifacts and findings from EIS's expeditions. Visitors can see a customized EIS camera, learn about the technological innovations EIS made to capture compelling images of glaciers, and gain knowledge of the physical demands team members face travelling to remote EIS field locations. Lastly, EIS photography has been embedded onto social media platforms (coded in red). Because social media is a form of new media, there is a certain level of user interactivity built into the platform. These qualities have made EIS photography highly spreadable since it is easy for users to disseminate the images within their own social networks. Hence, it is not surprising that audiovisual interviews of EIS members as well as EIS's videos have been widely circulated on the Internet from the webpages of mainstream news media to the feeds of users on Instagram, YouTube and Google Earth. Maintaining this active social media presence has enabled Internet users to follow EIS and engage with their story. They can do so by 


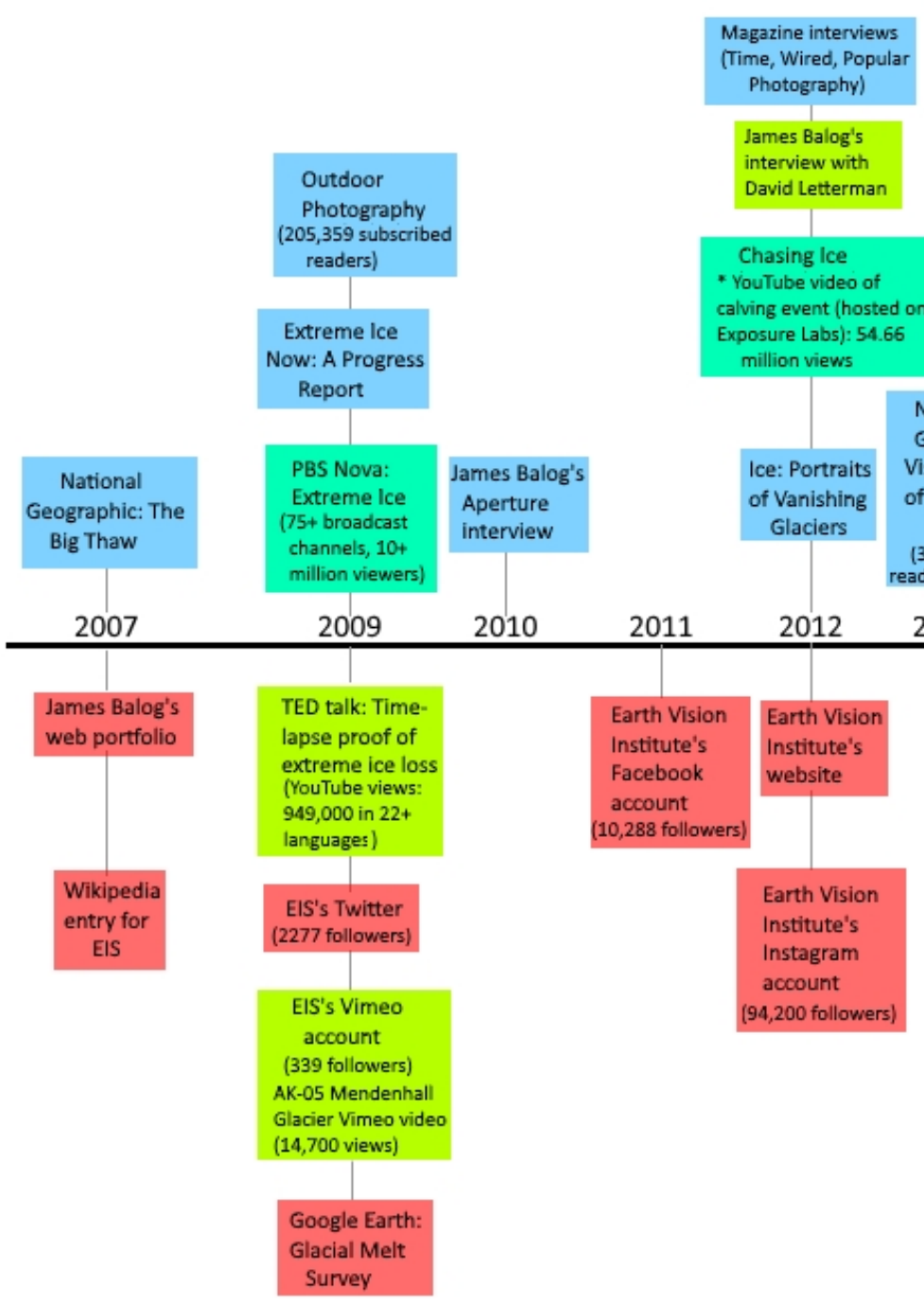

NEW MEDIA

Figure 1. Extreme Ice Survey in the media (2007-2017).

commenting on EIS content, sharing it within their social networks, or by subscribing to news feeds to keep informed of the latest EIS findings and updates.

\section{Continuity vs. multiplicity}

Jenkins [2009a] describes continuity and multiplicity as opposing core principles of transmedia storytelling. Continuity refers to the characteristics of a story that remain consistent across its many different embodiments. Multiplicity, by contrast, refers to the potential for the same story to be retold in myriad ways across different contexts and settings. Accordingly, successful transmedia storytelling demands "coordination across the different media sectors" [Jenkins, 2009a] that producers rely upon for dissemination. Hence, transmedia texts are most effective when the same artist or team members commit to shaping and consistently (re)telling a story for the different media contexts where it will be told [Jenkins, 2009a]. As both the primary author and coordinator of the EIS narrative, Balog and the EIS team have privileged and prioritized continuity over multiplicity. While 
EIS offers multiple photographic perspectives of retreating glaciers, the story of such retreat is conveyed consistently across a multitude of different platforms, contexts and settings. In so doing, there is a single unified storytelling experience for audiences rather than a story with mixed messages.

Further, to enhance its own scientific credibility, EIS has established its own historical continuity with past scientific expeditions, particularly to those in which photography was used to enable the public to vicariously witness natural phenomena. In addition to positioning Ernest Shackleton's $20^{\text {th }}$ century polar expeditions on the HMS Endurance as an important precursor to the EIS project [Burkhart et al., 2017, p. 3], Balog explains that "[m]uch like the Powell and Hayden expeditions to the American West during the $19^{\text {th }}$ century, EIS is an adventurous, and sometimes dangerous, undertaking" [Orlowski, 2012]. Here, Balog refers to geologist James Wesley Powell's geographic survey of the southwestern United States in 1867 and to Ferdinand Vandeveer Hayden's geological surveys in the 1870 s. He pays homage to these late $19^{\text {th }}$ century scientific expeditions as precursors to the EIS project because of the significant role "expeditionary photographers" [Taft, 1964] played in these endeavors. Accompanying scientists, expeditionary photographers often acted as direct eyewitnesses of natural phenomena that were geographically located in remote sites, requiring photographers to act as explorers of a new frontier. Akin to EIS's mission, the work of these $19^{\text {th }}$ century expeditionary photographers would, at times, offer scientific evidence to policy makers at critical decision-making junctures, particularly around the importance of preserving natural landscapes. For instance, William Henry Jackson, the official photographer on the Hayden expedition, exhibited his photographs of natural landscapes in 1872 in Congress to help pass a Senate Bill that led to the creation of Yellowstone National Park [Taft, 1964, p. 302]. By transforming senators into vicarious eyewitnesses of a region yet to be captured on film, Jackson's photographs impressed upon those politicians the immediate need to preserve the area. Jackson's photographs, like those produced by EIS, are not only impressive in terms of what they allow others to witness for the first time, but also because their existence is never guaranteed. The images are only made possible because expeditionary photographers transported their cameras and equipment over long and hazardous trails [Taft, 1964], overcoming great personal and technological challenges during their expeditions. In short, expeditionary photographers take on the role of adventurous hero, which, in turn, corresponds with the principle of performance.

\section{Performance}

In defining the term "performance," Jenkins refers to the ways audiences interact with transmedia texts and to the ways in which producers perform "... their relationships to both the text and the audience through their presence online or through director's commentary" [Jenkins, 2009b]. By tracing the EIS project back to the tradition of expeditionary photographers, Balog is able to represent himself as both a witness [Ritchin, 2010, p. 82], and more importantly, as an artist-scientist in the mould of the polar-explorer hero. While EIS is a contemporary photographic expedition unrivaled in terms of scale and scope, the narratives used to tell the story of its expedition resonate with a common theme in historical narratives of polar exploration - namely, the heroism attached to the polar explorer. Since the 
$19^{\text {th }}$ century, Arctic expedition narratives have been associated with "heroic adventure, patriotism, honour and manliness, as well as scientific progress" [Millar, 2015, p. 432], with Arctic photography often helping to consolidate, reproduce and naturalize the public's perception of the region. Central to these narratives, the polar-explorer hero appears to not only document his expedition through images - including self-portraits and portraits of "natives" (in EIS's case, the "natives" are glaciers) in the Arctic landscape - but to also bring an adventure narrative to the public's attention. Correspondingly, EIS's story of glacial retreat is inseparably intertwined with the story of EIS. That is, the EIS team has been repeatedly featured in their own stories about glacial retreat. Their appearance in these stories aligns with the narratives of polar explorer heroes. Like polar explorer heroes before them, members of the EIS team are on a mission of exploration, discovery and revelation, despite the many risks that they will encounter. These themes are clearly highlighted in the synopsis for Chasing Ice:

Traveling with a team of young adventurers across the brutal Arctic, Balog risks his career and his wellbeing in pursuit of the biggest story facing humanity. As the debate polarizes America, and the intensity of natural disasters ramps up globally, Chasing Ice depicts a heroic photojournalist on a mission to deliver fragile hope to our carbon-powered planet [Submarine Deluxe, 2012].

The performativity of this thematic storyline is evidenced in Balog's numerous interviews and public engagements, where he promotes the work of EIS by presenting himself as a compelling media spokesperson for glaciers. The "Marketing Toolkit" for Balog's Keppler Speakers profile, a PR firm that promotes prestigious celebrity speakers, demonstrates how he merges this spokesperson role into that of a media personality. As the public face of EIS, his access to the lecture circuit allows him to contextualize EIS's images. While these "images provide the 'smoking gun' of climate change, visual evidence that audiences young and old can understand" [Keppler Speakers, 2018], Balog's lectures ensure that audiences understand the energy, effort and risk-taking required to produce those photographs. The "visual voice" [University of Buffalo, 2018] of the glaciers is magnified by Balog's own charismatic voice, and his own professional networks. For instance, he has taken advantage of his longstanding ties to the National Geographic Society, not only one of the world's largest scientific and educational media operations, but also an early precursor to emerging transmedia storytelling approaches to journalism [Moloney, 2012].

Conclusion: extractible EIS
Using EIS as a case study, this article has demonstrated how climate science can be effectively communicated to a wider audience through the interrelated concepts of witnessing and transmedia storytelling. EIS's story of vanishing glaciers has reached multiple audiences through its circulation across different media platforms, inviting audience members to engage with climate science. Because of the story's ability to be performed and distributed in different forms - whether as part of an art exhibition, museum display, late-night television interview, documentary film, YouTube video, or collection of placemarks in Google Earth — it has spread widely across the media landscape [Jenkins, Ford and Green, 2013], particularly in North America. As a story that has continuity as well as immersive 
and drillable qualities, audience members are able to interact with EIS's findings in diverse ways, depending on their own level of engagement and commitment.

Some may seek to learn more about glacial retreat and climate change, or take some form of climate action. Others may simply become aware of the issue of extreme ice loss, and its connection to climate change. Across this continuum of audience engagement and interactivity, it should be noted that audiences are assumed to be active, even if they do no more than listen to the EIS story.

By positioning its time-lapse animations of glacier melt as demonstrative evidence of climate change, EIS has positioned its audience as vicarious witnesses who bear some responsibility for what they are seeing. As Balog puts it,

In this ice project we are witnessing things that are beyond the normal imagination of humans, and in witnessing them and documenting them, we grab you by the shoulders and say: 'Pay attention; here it is. You can't pretend it isn't happening' [Ritchin, 2010, p. 82].

Because the EIS project links witnessing to a change in perception (i.e., a change in belief) - after all, "seeing is believing" is the subtitle of the EIS project [Ritchin, 2010, p. 82] — it is worth considering Henry Jenkins' principle of extractability, in order to discuss the project's impact on audiences. As one of the core principles of transmedia storytelling, and perhaps one of the most important principles associated with climate action, extractability refers to the aspects of the story that audiences can take away with them as resources to deploy in their everyday lives [Jenkins, 2009b]. While there are extractable elements to the EIS story, whether expressed as facts in Chasing Ice and on the EIS website, or as "further reading material" and data sources at the end of Balog's books, there is a remarkable difference between producing a story with extractable elements and how audiences actually engage with that story. Given our methodology, we are unable to offer insights on how diverse audiences actually interacted with the EIS project, nor on the extent to which the EIS story has resulted in meaningful public action.

Hence, we urge future research to consider how audiences engage with scientific storytelling by asking: how do audiences encounter and react to scientific narratives? How do they choose to access and enter into the story itself? Moreover, what effects do transmedia narratives have on audiences for more sustained forms of engagement and potential action? At what level - individual, collective, or systemic - do audiences conceptualize such action? Responding to these questions would help elaborate on the ways in which transmedia storytelling could be a valuable model for communicating science and scientific findings to more general audiences. Such future research could also clarify whether transmedia storytelling facilitates more participatory engagements with climate science than the deficit model of science communication, and whether these audience interactions allow for greater knowledge of and connection to issues of climate science.

References

American Society of Media Photographers (31st December 2013). 'Cover artist: James Balog'. ASMP Bulletin Magazine. URL: https://www . asmp .org/bulletinmagazine/cover-artist-james-balog/. 
Appenzeller, T. (6th June 2007). 'The big thaw'. National Geographic. URL: http://ng m.nationalgeographic.com/2007/06/big-thaw/big-thaw-text.

Balog, J. (2009a). Extreme ice now. Washington, DC, U.S.A.: National Geographic Society.

- (2009b). Time-lapse proof of extreme ice loss. [TED talk]. URL: https : //www . ted.co m/talks/james_balog_time_lapse_proof_of_extreme_ice_loss.

Barthes, R. (1972). Mythologies. New York, NY, U.S.A.: Farrar, Straus and Giroux.

- (1977). Image, music, text. New York, NY, U.S.A.: Hill and Wang.

Bensaude Vincent, B. (2014). 'The politics of buzzwords at the interface of technoscience, market and society: The case of "public engagement in science"'. Public Understanding of Science 23 (3), pp. 238-253. https://doi.org/10.1177/0963662513515371.

Boykoff, M. T. and Boykoff, J. M. (2004). 'Balance as bias: global warming and the US prestige press'. Global Environmental Change 14 (2), pp. 125-136. https://doi.org/10.1016/j.gloenvcha.2003.10.001.

Bryman, A. (2004). Social research methods. Oxford, U.K.: Oxford University Press.

Bucchi, M. (2008). 'Of deficits, deviations and dialogues: theories of public communication of science'. In: Handbook of Public Communication of Science and Technology. Ed. by M. Bucchi and B. Trench. London, U.K. and New York, U.S.A.: Routledge, pp. 57-76.

Burkhart, P. A., Alley, R. B., Thompson, L. G., Balog, J. D., Baldauf, P. E. and Baker, G. S. (2017). 'Savor the cryosphere'. GSA Today, pp. 4-11. https://doi.org/10.1130/gsatg293a.1.

Cody, E. M., Reagan, A. J., Mitchell, L., Dodds, P. S. and Danforth, C. M. (2015). 'Climate change sentiment on Twitter: an unsolicited public opinion poll'. PLOS ONE 10 (8). Ed. by S. Lehmann, e0136092. https://doi.org/10.1371/journal.pone.0136092.

Daston, L. and Galison, P. (2007). Objectivity. New York, NY, U.S.A.: Zone Books.

Doyle, J. (2007). 'Picturing the clima(c)tic: Greenpeace and the representational politics of climate change communication'. Science as Culture 16 (2), pp. 129-150. https://doi.org/10.1080/09505430701368938.

Ellis, J. (2000). Seeing things: television in the age of uncertainty. London, U.K.: IB Tauris.

Gaycken, O. (2012). 'The secret life of plants: visualizing vegetative movement, 1880-1903'. Early Popular Visual Culture 10 (1), pp. 51-69. https://doi.org/10.1080/17460654.2012.637392.

Golan, T. (2004). 'The emergence of the silent witness: the legal and medical reception of X-rays in the U.S.A.' Social Studies of Science 34 (4), pp. 469-499. https://doi.org/10.1177/0306312704045705.

Harvey, C. (3rd April 2017). 'These stunning timelapse photos may just convince you about climate change'. The Washington Post. URL: https://www . washingtonpost. com/news/energy-environment/wp/2017 104/03/you-cant-deny-climate-change-once-you-see-these-images/.

Howie, L. (2012). Witnesses to terror. London, U.K.: Palgrave.

Jasanoff, S. (1992). 'What judges should know about the sociology of science'. Jurimetrics 32 (3), pp. 345-359. URL: https://www . jstor .org/stable/29762258. 
Jenkins, H. (12th December 2009a). 'The revenge of the origami unicorn: seven principles of transmedia storytelling'. Confessions of an Aca-Fan. URL: http://he nryjenkins.org/blog/2009/12/the_revenge_of_the_origami_uni.html.

- (12th December 2009b). 'The revenge of the origami unicorn: the remaining four principles of transmedia storytelling'. Confessions of an Aca-Fan. URL: http://he nryjenkins.org/blog/2009/12/revenge_of_the_origami_unicorn.html.

Jenkins, H., Ford, S. and Green, J. (2013). Spreadable media. New York, NY, U.S.A.: NYU Press.

Jenkins, H. (2006). Convergence culture: where old and new media collide. New York, U.S.A.: New York University Press.

Keppler Speakers (2018). James Balog: marketing toolkit. URL: https://www . kepplerspeakers . com/speakers/james-balog.

León, B. and Erviti, M. C. (2015). 'Science in pictures: Visual representation of climate change in Spain's television news'. Public Understanding of Science 24 (2), pp. 183-199. https://doi.org/10.1177/0963662513500196.

Millar, P. (2015). 'Frederick A. Cook: the role of photography in the making of his polar explorer-hero image'. Polar Record 51 (04), pp. 432-443. https://doi.org/10.1017/s0032247414000424.

Mnookin, J. L. (1998). 'The image of truth: photographic evidence and the power of analogy'. Yale Journal of Law \& the Humanities 10 (1), pp. 1-74.

URL: https://digitalcommons.law.yale.edu/yjlh/vol10/iss1/1.

Moloney, K. (2012). 'Transmedia journalism as a post-digital narrative'.

URL: https://transmediajournalism.org/2012/11/05/transmedia-journali sm-as-a-post-digital-narrative/.

Moloney, K. and Unger, M. (2014). 'Transmedia storytelling in science communication: one subject, multiple media, unlimited stories'. In: New trends in earth-science outreach and engagement. Ed. by J. L. Drake, Y. Y. Kontar and G. S. Rife. Berlin, Germany: Springer International Publishing, pp. 109-120. https://doi.org/10.1007/978-3-319-01821-8_8.

Moser, S. C. (2009). 'Communicating climate change: history, challenges, process and future directions'. Wiley Interdisciplinary Reviews: Climate Change 1 (1), pp. 31-53. https://doi.org/10.1002/wcc.11.

- (2016). 'Reflections on climate change communication research and practice in the second decade of the 21st century: what more is there to say?' Wiley Interdisciplinary Reviews: Climate Change 7 (3), pp. 345-369. https://doi.org/10.1002/wcc. 403.

Moser, S. C. and Dilling, L. (2011). 'Communicating climate change: closing the science-action gap'. In: The Oxford handbook of climate change and society. Ed. by J. S. Dryzek, R. B. Norgaard and D. Schlosberg. Oxford, U.K.: Oxford University Press, pp. 161-174. https://doi.org/10.1093/oxfordhb/9780199566600.003.0011.

Moutinho, A. (9th November 2017). 'Photographer James Balog captures glaciers, before they're gone'. Boulder Weekly. URL: http: //www . boulderweekly . com/bou lderganic/photographer-james-balog-captures-glaciers-theyre-gone/.

Nisbet, M. C. (2009). 'Communicating climate change: why frames matter for public engagement'. Environment: Science and Policy for Sustainable Development 51 (2), pp. 12-23. https://doi.org/10.3200/ENVT.51.2.12-23. 
O'Neill, S. J. and Smith, N. (2014). 'Climate change and visual imagery'. Wiley Interdisciplinary Reviews: Climate Change 5 (1), pp. 73-87.

https://doi.org/10.1002/wcc. 249.

Open Space Institute (2018). 'James Balog'. Honoring the Future. URL: https : //www . honoringthefuture org/climate-smarts/artist-to-know/james-balog/.

Orlowski, J. (2012). Chasing ice. [motion picture]. U.S.A.

Painter, J. (2010). Summoned by science: reporting climate change at Copenhagen and beyond. Oxford, U.K.: Reuters Institute for the Study of Journalism.

Parkinson, D. (1995). History of film. New York, NY, U.S.A.: Thames and Hudson.

Peters, J. D. (2001). 'Witnessing'. Media, Culture E Society 23 (6), pp. 707-723. https://doi.org/10.1177/016344301023006002.

Ritchin, F. (2010). 'Of art and ice: James Balog'. Aperture 198, pp. 80-83.

Rothman, L. (12th March 2012). 'Chasing ice: could time-lapse photography save the planet?' Time Magazine. URL: http://time.com/3786950/chasing-ice/.

Sakellari, M. (2015). 'Cinematic climate change, a promising perspective on climate change communication'. Public Understanding of Science 24 (7), pp. 827-841. https://doi.org/10.1177/0963662514537028.

Shapin, S. and Schaffer, S. (1985). Leviathan and the Air-Pump: Hobbes, Boyle, and the experimental life. Princeton, NJ, U.S.A.: Princeton University Press.

Smith, N. W. and Joffe, H. (2009). 'Climate change in the British press: the role of the visual'. Journal of Risk Research 12 (5), pp. 647-663. https://doi.org/10.1080/13669870802586512.

Smith, R. and Wynne, B., eds. (1989). Expert evidence. London, U.K.: Routledge.

Submarine Deluxe (2012). Press kit for chasing ice. URL: https : //chasingice. com/wp - content/uploads/2014/03/Chasing-Ice-Production-Notes-10-3-12 .pdf.

Taft, H. (1964). Photography and the American scene. New York, NY, U.S.A.: Dover Publications.

Trench, B. (2008). 'Towards an analytical framework of science communication models'. In: Communicating science in social contexts. Ed. by D. Cheng, M. Claessens, T. Gascoigne, J. Metcalfe, B. Schiele and S. Shi. Dordrecht, Netherlands: Springer, pp. 119-135. https://doi.org/10.1007/978-1-4020-8598-7.

University of Buffalo (2018). Distinguished speaker series: James Balog. Buffalo, NY, U.S.A. URL: http://www . buffalo. edu/ub-speakers/speakers . html.

Urry, J. (2009). 'Speeding up and slowing down'. In: High-speed society. Ed. by H. Rosa and E. W. Scheurman. University Park, PA, U.S.A.: Pennsylvania State University Press, pp. 179-198.

Williams, H. T. P., McMurray, J. R., Kurz, T. and Hugo Lambert, F. (2015). 'Network analysis reveals open forums and echo chambers in social media discussions of climate change'. Global Environmental Change 32, pp. 126-138. https://doi.org/10.1016/j.gloenvcha.2015.03.006. 
Anita Lam is an Associate Professor of Criminology at York University, Canada. Her research is situated at the intersection of crime, media and culture.

E-mail: lamanita@yorku.ca.

Matthew Tegelberg is an Assistant Professor in the Department of Social Science at York University, Canada. His research concentrates on media representations of climate change and tourism. E-mail: mtegel@yorku.ca. transmedia storytelling'. JCOM 18 (02), A05. https:/ / doi.org/10.22323/2.18020205. 